\title{
DESENVOLVIMENTO E APLICAÇÃO DE UM BANCO DE DADOS GEOGRÁFICOS NA ELABORAÇÃO DE MAPAS DA MORFODINÂMICA COSTEIRA E SENSIBILIDADE AMBIENTAL AO DERRAMAMENTO DE ÓLEO EM ÁREAS COSTEIRAS LOCALIZADAS NO ESTADO DO RIO GRANDE DO NORTE
}

\author{
ANGÉLICA FÉLIX DE CASTRO, MICHAEL VANDESTEEN S. SOUTO, \\ VENERANDO EUSTÁQUIO AMARO \& HELENICE VITAL
}

\begin{abstract}
TITULO VERTIDO PARA O IDIOMAINGLÊS) The coastal area of northern Rio Grande do Norte State is submitted to intense and constant processes of littoral and aeolian transport, causing erosion, alteration in the sediment balance and modifications of the shoreline. Beyond these natural factors, human interference is huge in the surroundings due to the Guamaré Petroliferous Pole nearby, the largest terrestrial oil producer in Brazil. There is a bulky amount of data from the study area such as geologic and geophysical multitemporal data, hydrodynamic measurements and remote sensing multitemporal images, among others; it is extremely important to elaborate a Geographic Database (GD), one of the main components of a Geographic Information System (GIS), to store the information, allowing the access to researchers and users. The first part of this work consisted of elaboration a GD to store the data of the study area. The main goal was to use the potentiality of the GIS as a tool to support decisions related to the environmental monitoring of this region, a valuable target for oil exploration, salt companies and shrimp farms. The collected data was stored as a virtual library to assist human decision-making from the results presented as digital thematic maps, tables and reports, useful as a source of data in the preventive planning and as guidelines to the future research themes both on regional and local context. The second stage of this work consisted of elaborating the Coastal Morphodinamics Maps and Oil-Spill Environmental Sensitivity Maps. These maps were important in the study of the area, to determine the present situation of the area, evaluating its potentials and fragilities.
\end{abstract}

Keywords: database geographic, oil-spill environmental sensitivity, coastal morphodinamycs

\begin{abstract}
Resumo As áreas costeiras localizadas na parte setentrional do Estado do Rio Grande do Norte, caracterizam-se por sofrer constantes processos de transporte litorâneo e eólico, ocasionando erosão, alterações no balanço de sedimentos e modificações na linha de costa. Além desses fatores naturais, a interferência antrópica é ampla nas redondezas, visto a proximidade ao Pólo Petrolífero de Guamaré, o maior produtor terrestre de petróleo do Brasil. Pelo fato de existirem vários tipos de dados desta área de estudo, tais como dados geológicos e geofísicos multitemporais, dados hidrodinâmicos e produtos de sensoriamento remoto, entre outros; é de extrema importância a elaboração de um Banco de Dados Geográficos (BDG), um dos principais componentes dos Sistemas de Informações Geográficas (SIGs), para armazenar toda essa quantidade de informação, permitindo o acesso a pesquisadores e usuários interessados. A primeira parte desse trabalho consistiu em elaborar e desenvolver um BDG a fim de armazenar todos os dados existentes da área de estudo. A intenção foi utilizar a potencialidade do SIG como ferramenta importante no apoio às tomadas de decisões no monitoramento ambiental desta região, alvo de ampla exploração da indústria petrolífera, salineira e de carcinocultura. Os dados coletados e armazenados na forma de uma biblioteca virtual tendem a auxiliar nas tomadas de decisões a partir dos resultados apresentados sob a forma de mapas temáticos digitais, tabelas e relatórios, úteis como fonte de dados no planejamento preventivo e na definição das linhas de pesquisas futuras que serão desenvolvidas nesta região, tanto no contexto regional como no contexto local. A segunda etapa deste trabalho consistiu em elaborar, a partir dos dados previamente armazenados no BDG, Mapas da Morfodinâmica Costeira e Mapas de Sensibilidade Ambiental ao Derramamento de Óleo. Esses mapas foram de fundamental importância na avaliação da área, a fim de determinar a atual situação da área, avaliando seus potenciais e suas fragilidades.
\end{abstract}

Palavras-chaves: bancos de dados geográficos, sensibilidade ambiental ao derramamento de óleo, morfodinâmica costeira

INTRODUÇ̃̃O Atualmente, a preocupação com fatores ambientais é uma realidade em todos os setores da sociedade, principalmente pesquisadores e profissionais que trabalham diretamente com a situação do meio ambiente. Em 1972, durante a Conferência das Nações Unidas sobre Meio Ambiente em Esto- colmo, Suécia, foi enfatizada a idéia de que o homem, ao final do século XX, se tornaria o co-agente mais importante no processo geral de evolução da terra, capaz de intervir de maneira significativa nas transformações em curso do nosso planeta. De fato, o homem hoje em dia é o agente mais ativo quando o assunto é

Universidade Federal do Rio Grande do Norte, Departamento de Geologia, Programa de Pós-Graduação em Geodinâmica e Geofísica, CEP:59078-970. Natal - RN - \{angelica@summer.com.br, michaels_br@yahoo.com.br, amaro@geologia.ufrn.br, helenice@geologia,ufrn.br\} 
modificar o ambiente em que se vive, mesmo que essa modificação seja de maneira desordenada e descontrolada. Devido a isso, existe uma preocupação quanto à organização do espaço, de modo que essas mudanças agridam o mínimo possível o meio ambiente. A partir dessa preocupação, vários estudos sobre impactos ambientais estão sendo realizados no propósito de avaliar e proteger as regiões mais sensíveis às modificações. Neste sentido, a utilização do Geoprocessamento possibilita o tratamento eficaz e rápido dos dados ambientais, agilizando a execução do processamento desses dados e garantindo confiabilidade aos resultados finais obtidos.

O presente trabalho visa a análise e avaliação de áreas costeiras localizadas na porção setentrional do Estado do Rio Grande do Norte, por meio do uso de Geoprocessamento, desenvolvimento de um Banco de Dados Geográficos e aplicação de técnicas de Processamento Digital de Imagens. O emprego dessas tecnologias permitiu identificar a vulnerabilidade ambiental, a variação da morfodinâmica e a sensibilidade ambiental da área de estudo ao impacto causado pelo derramamento de óleo.

CARACTERIZAÇÃO DA ÁREA DE ESTUDO Aárea de estudo está inserida no contexto geológico da Bacia Potiguar, localizada no Nordeste do Brasil, na porção setentrional do Estado do Rio Grande do Norte, englobando parte da margem costeira norte do estado (Fig. 1). Foram selecionados quatro municípios vizinhos São Bento do Norte, Galinhos, Guamaré e Macau - que foram estudados, analisados e avaliados.

Características geológicas A geologia da área de estudo se insere no contexto do domínio da Bacia Potiguar (Cretáceo). Entretanto, predominam na região sedimentos pertencentes ao Grupo Barreiras do Terciário, formadores de solos arenosos e arenoargilosos creme e creme-avermelhados, que cobrem os calcários da Formação Jandaíra, que ocorrem somente em subsuperfície. No litoral, o Grupo Barreiras encontra-se coberto por dunas arenoquartzosas. Em Galinhos destaca-se uma faixa estuarina onde predominam os aluviões recentes, com solos areno-argiloso com muita matéria orgânica.

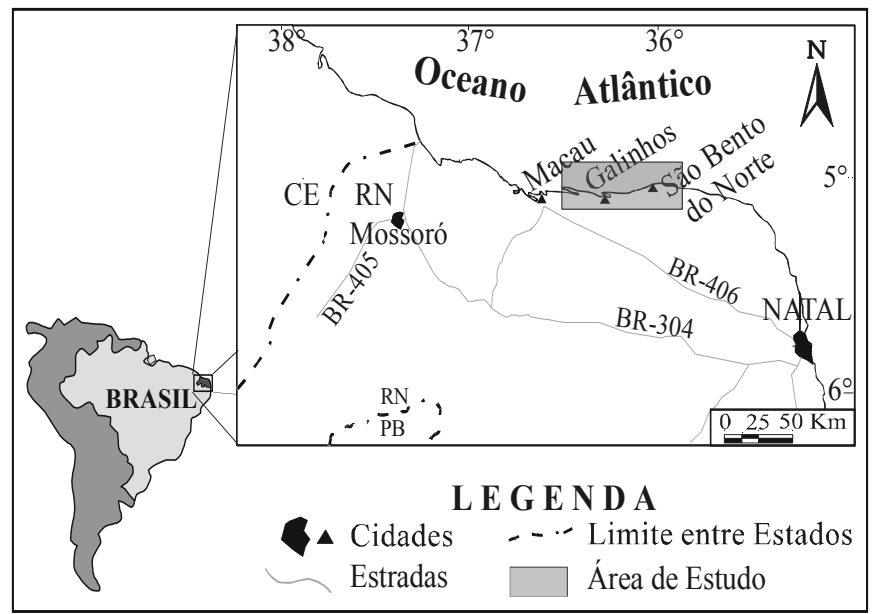

Figura 1 - Mapa de localização geográfica da área de trabalho, englobando os municípos de São Bento do Norte, Galinhos e Macau, Estado do Rio Grande do Norte.
Toda a área encontra-se inserida na zona costeira e possui sedimentos e rochas sedimentares que representam depósitos cenozóicos de sistemas deposicionais costeiros (Caldas 1998). Trata-se de áreas marcadas fortemente por processos costeiros deposicionais e erosionais causados pela ação conjunta dos ventos, correntes, ondas e marés (Hustedt 2000).

Do litoral para o interior, ocorre uma seqüência de sedimentos quaternários (dunas, paleodunas e aluviões), arenitos do Grupo Barreiras e calcários da Formação Jandaíra (Secretaria de Recursos Hídricos 2001). Em São Bento é marcante a presença de bancos de arenitos, dunas móveis, paleodunas, paleodunas descaracterizadas, paleocordões arenosos, concheiros, depósitos de paleoplanície de maré e de calcários. As paleodunas descaracterizadas e as dunas móveis predominam nessa área (Caldas 1996).

A geologia do município de Galinhos é formada por seqüências sedimentares do Grupo Apodi, representado pelas formações Alagamar, Açu, Jandaíra, Macau, Guamaré e Tibau (Lima et al. 2000). Caracteriza-se por depósitos praiais, eólicos, marinhos e estuarinos, onde a erosão constante e o retrabalhamento da zona costeira dão origem às seqüências de areias praiais mal selecionadas, areias praiais e eólicas, areias eólicas de granulometria fina a média, vasas arenosas orgânicas e/ou argilo-arenosas orgânicas (Lima 1993). Caldas (1998) salienta a presença marcante de beachrocks situados entre as cidades de São Bento do Norte e Galinhos. Esses beachrocks são constituídos de arenitos finos a muito grossosa, subordinadamente areia muito grossa até seixo. $\mathrm{Na}$ área de São Bento, os beachrocks têm direção aproximada leste-oeste com as fraturas principais paralelas ou transversais.

Características geomorfológicas O relevo da área apresenta paisagem monótona próximo ao litoral, com a presença de uma ampla planície de maré. Nessa faixa litorânea, as altitudes geralmente estão situadas ao nível médio dos mares (Dantas 1998). Esta região sofre constantes modificações geomorfológicas, erosionais ou deposicionais, causadas principalmente por processos marinhos (Caldas 1998).

Na paisagem costeira, o modelamento das formas de relevo é resultante da ação constante dos processos do meio físico, tais como condições climáticas, variações do nível do mar, natureza das seqüências geológicas, atividades neotectônicas e suprimento de sedimentos carreados pelos rios e oceano.

Para Silveira $(2001,2002)$, a evolução ambiental dessas feições geomorfológicas tem seu paleoambiente relacionada à feição de baía estuarina, em períodos com níveis do mar mais elevados. A modificação deste ambiente ocorreu no Quaternário, decorrente da estabilização do nível do mar em sua posição atual, promovendo a formação de barras arenosas próximas à costa e o surgimento de terraços adjacentes e/ou circunvizinhos às águas estuarinas, que têm o fluxo e refluxo ocorrendo nos diversos canais da planície estuarina. A morfologia atual da região permite o ingresso da maré nos rios e gamboas e por vezes, na fase equinocial, barras arenosas, terraços flúvio-marinho e terraços estuarinos em algumas das áreas. As condições climáticas atuais, associadas à natureza e suprimento dos sedimentos, e a aspectos da dinâmica oceanográfica, têm propiciado o desenvolvimento de feições erosivas e construtivas na faixa litorânea; esta instabilidade pode ser constatada pela progradação da linha da costa, ocasionada por meio da formação de extensos depósitos arenosos e areno-argilosos com superfície plana a suavemente ondulada; barra arenosa; zonas de estirâncio e dunas costeiras. 
As formas deposicionais são as dunas móveis e fixas, os cúspides praiais e as planícies arenosas sem feições geomorfológicas marcantes. Como formas erosionais destacamse as falésias marinhas vivas, que sofrem ação erosiva das ondas diretamente (Caldas 1996). De acordo com Caldas (1998), os beachrocks a leste de São Bento do Norte desenvolvem escarpas ao longo da praia, com diferenças de cotas da ordem de 4 a 5 metros. Atualmente as dunas existentes nas praias de São Bento do Norte são responsáveis por boa parte dos sedimentos que se deslocam em direção à cidade (Tabosa 2001).

De acordo com Lima (1993), Galinhos é formado morfologicamente por planícies costeiras e superfície de aplainamento. Trata-se de uma região com praias arenosas e planas. Suas principais feições geomorfológicas são representadas por praias, recifes, estuários, mangues, laguna, lagoas e dunas. O modelamento dessas feições é fruto da atuação conjunta de ondas, correntes costeiras e ventos, relacionado com a variação do nível do mar (Lima et. al 2000). Atualmente, o avanço do campo de dunas móveis está soterrando a vegetação de mangue e assoreando o canal de maré. Além disso, Galinhos está situado em um esporão (spit) de direção E-W, com aproximadamente 9,5 km de extensão e largura média de $550 \mathrm{~m}$ (Lima et. al 2001).

\section{A IMPORTÂNCIA DO GEOPROCESSAMENTO E DOBAN- CODE DADOS GEOGRÁFICOSDA ÁREA DE ESTUDO As vantagens do Geoprocessamento, bem como a funcionalidade dos seus componentes, foram imprescindíveis no desenvolvimento deste trabalho. O Geoprocessamento pode ser definido como uma ferramenta para o planejamento e controle ambiental como tam- bém um instrumento de suporte à decisão: é a união de uma Base de Dados Georreferenciada com técnicas para aquisição de da- dos, atualização, processamento e visualização de resultados (Bahr \& Karlsruhe 1999). Esta definição inclui não apenas aquisição e processamento de dados, mas também tomadas de decisão. A capacidade de tomada de decisões é uma característica dos seres humanos; somente ele é capaz de assumir suas responsabilida- des. Entretanto, o Geoprocessamento auxilia nas decisões mais complexas, como planejar o desenvolvimento ou monitorar o am- biente em que ele habita.}

As ferramentas computacionais do Geoprocessamento são os Sistemas de Informações Geográficas (SIG). Eles realizam análises complexas, ao integrar dados alfanuméricos com dados geográficos de uma determinada área de estudo, através de um banco de dados georreferenciados. Os SIGs têm a capacidade de manipular dados espaciais (cartográficos, cadastrais, sensoriamento remoto, modelos numéricos de terreno) e dados não-espaciais (descritivos ou alfanuméricos), de forma integrada, provendo uma base consistente para análise e consulta. Logo, é possível ter acesso às informações descritivas de uma entidade geográfica a partir de sua localização geográfica e vice-versa (Filho 1997).

O nível de armazenamento de um SIG, o Banco de Dados Geográficos (BDG) propriamente dito foi o foco principal deste trabalho. O BDG pertence à categoria dos bancos de dados não-convencionais e caracteriza-se não somente pelo armazenamento de dados, como também pelo relacionamento deles com suas respectivas posições geográficas.

Os SIGs utilizam duas formas de armazenamento de dados geográficos no BDG: forma matricial e forma vetorial. A forma matricial divide o espaço em grades regulares, freqüentemente associado ao pixel, ao qual é atribuído um valor único, que determina o tipo de objeto ou a condição daquele determinado ponto. Já o modelo vetorial usa as entidades ponto, linha e polígono para representar objetos e condições do mundo real.

Projeto de um banco de dados geográficos Projetar um Banco de Dados Geográficos (BDG) é de extrema importância. Envolve decisões em diferentes níveis e requer o uso de diferentes instrumentos, uma vez que as atividades necessárias a sua elaboração variam de acordo com a complexidade do sistema, com o tipo de pessoal envolvido, o SGBD utilizado, além de outros fatores (Gomes 1997 \& Filho et.al 1999). Desta forma, o desenvolvimento de sistemas de banco de dados deve estar baseado em uma metodologia eficaz, a partir da qual são empregados instrumentos específicos de apoio às diferentes etapas do projeto.

Durante essa fase de modelagem, se faz necessário identificar todos os objetos do mundo real que de alguma forma irão interferir no sistema. É uma descrição geral das entidades envolvidas e os relacionamentos existentes entre elas.

O sucesso da implementação de um sistema de informação é dependente da qualidade dessa modelagem, pois é nela que é feita a transposição dos objetos do mundo real e suas interações para um banco de dados informatizado. Isto é especialmente válido em um SIG, onde o processo de modelagem de dados precisa considerar não apenas o conjunto de dados descritivos de um objeto e seu relacionamento com as demais, mas também exige escolher uma representação a adotar para cada entidade. Dessa forma, o projeto de banco de dados compreende três modelos básicos (Gomes 1997, Filho 2000, Heuser 2001):

MODELO CONCEITUAL O Modelo Conceitual é a descrição do banco de dados, onde, a partir da especificação de requisitos, são representadas quais as entidades (descritas por seus atributos) serão armazenadas no banco de dados e os relacionamentos existentes entre elas. Nesta fase, não são considerados aspectos de implementação e quais sistemas de computação (software/ hardware) que serão utilizados.

MODELO LÓGICO A partir do modelo conceitual é gerado o modelo lógico. Neste nível é definido como as entidades serão armazenadas na estrutura do BD (em tabelas, por exemplo). Assim, o modelo lógico depende do tipo de SGBD que será utilizado na implementação.

MODELO FÍSICO Nessa etapa são definidos detalhes de implementação dos dados, descrevendo a estrutura de armazenamento e os métodos utilizados para acessar os dados efetivamente. Estes fatores estão, diretamente, relacionados a um SGBD específico e permitem, ao projetista, planejar aspectos ligados à eficiência do sistema de banco de dados. Estas fases de modelagem estão representadas na Figura 2.

Seguindo essa metodologia, foi possível modelar e desenvolver um Banco de Dados Geográficos contendo todas as informações importantes da área de estudo, a fim de que esses dados pudessem ser acessados futuramente para análise e obtenção de resultados da área.

\section{PROJETO E DESENVOLVIMENTO DO BANCO DE DADOS} GEOGRÁFICOSDA ÁREA DE ESTUDO Diante da necessidade de armazenar em uma única base de dados todos os dados da área de estudo provenientes de trabalhos de campo, de pesquisas na literatura, material adquirido (tais como imagens de satélite) dentre outras fontes; foi projetado e desenvolvido um banco de 


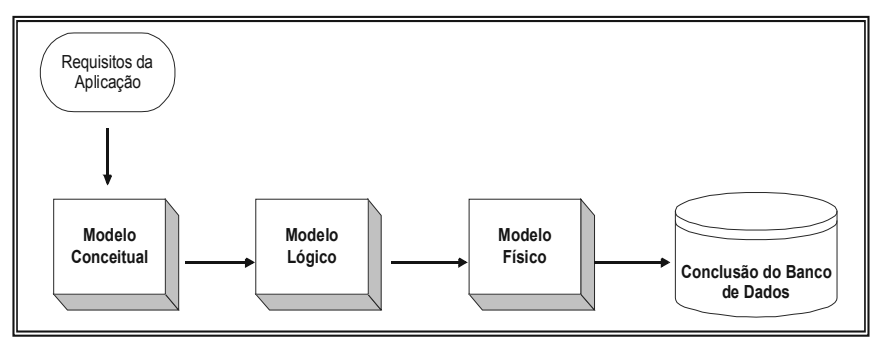

Figura 2 - Etapas gerais de um Projeto de Banco de Dados Geográficos

dados em ambiente SIG que suportasse dados descritivos e geográficos.

Modelagem conceitual A modelagem conceitual adotada nesse trabalho foi o GeoFrame, um modelo desenvolvido pelo grupo de pesquisa em banco de dados geográficos do Instituto de Informática da Universidade Federal do Rio Grande do Sul (UFRGS). O GeoFrame é um framework conceitual que fornece um diagrama de classes básicas para auxiliar o projetista na modelagem conceitual de dados geográficos (Filho et.al 1999). Framework é composto por um conjunto de classes e pode ser definido como uma estrutura (ou esqueleto) de implementação de uma aplicação ou de um subsistema de aplicação, em um domínio de problema particular. O conceito de diagramas de classe utilizado baseia-se na notação UML (Unified Modeling Language); que é uma linguagem própria para modelagem de sistemas, usando conceitos orientados a objetos (Larman 2000).

Geoframe é composto por três etapas. Inicialmente são identificados, para cada área geográfica, os diversos temas (e subtemas) a serem projetados. Na segunda etapa é definido um subesquema de classes para cada tema identificado. Ainda nessa etapa, é feita a especificação das associações entre classes de diferentes temas. Por último, são realizadas a análise e modelagem do tipo de representação espacial de cada fenômeno geográfico identificado. O GeoFrame possui algumas particularidades para representar dados geográficos e convencionais, bem como a representação de geo-campos e geo-objetos. Os geo-objetos se subdividem em Ponto, Linha, Polígono e Objeto Espacial Complexo, enquanto que os geo-campos podem ser do tipo Amostragem Irregular de Pontos (medição de temperatura), Linhas de Contorno (curvas de nível), Polígonos Adjacentes (tipos de solo, por exemplo), Amostragem Regular de Pontos (Modelo Numérico de Terreno), Grade Regular de Células (imagens de satélite) e Rede Triangular Irregular. Além disso, existe o conceito $<<$ função $>>$ que nada mais é que a relação entre classes (objeto convencional, geo-campos e geo-objetos). A Figura 3 resume os principais termos de SIG usados na modelagem GeoFrame.

PRIMEIRA ETAPADA MODELAGEM Na primeira fase da modelagem conceitual usando o GeoFrame, define-se a região geográfica a ser estudada e os temas mais genéricos a serem representados. Os dados da área de estudo são oriundos de fontes distintas e são de diferentes categorias. Devido a isso, procurou-se agrupálos de acordo com características semelhantes:

Dados Hidrodinâmicos - retratam os principais aspectos da dinâmica costeira (ventos, correntes, ondas, marés);

Dados de Perfis de Praia - levantamento mensal de perfis topo-

\begin{tabular}{|c|c|c|}
\hline $\begin{array}{l}\text { Fenômeno geográfico e } \\
\text { Objeto convencional }\end{array}$ & $\begin{array}{l}\text { Componente espacial } \\
\text { de objetos geográficos }\end{array}$ & $\begin{array}{l}\text { Componente espacial } \\
\text { de campos geográficos }\end{array}$ \\
\hline$\Theta$ Objeto geográfico & - Ponto & $\because$ Pontos irregulares \\
\hline A Campo geográfico & Linha & ::: Grade de pontos \\
\hline & $\square$ Poligono & Polígonos adjacentes \\
\hline$\triangle$ Objeto não geográfico & * Obj. espacial complexo & Isolinhas \\
\hline \multicolumn{2}{|c|}{ « função » função categórica } & TIN \\
\hline
\end{tabular}

Figura 3 - Estereótipos do Modelo GeoFrame (Filho 2000) utilizados no BDG para o derramamento de óleo.

gráficos da zona de praia e da caracterização ambiental praial;

Dados Geofísicos, coletados através de equipamentos apropriados, tais como o Ecobatímetro que registra a morfologia do fundo marinho, o Side Scan Sonar que registra lateralmente a textura do fundo marinho, o Radar de Penetração no Solo (GPR), que registra as variações elétricas de uma localização terrestre e o Perfilador de Correntes Acústico Doppler (ADCP), que mede direção e intensidade da corrente em tempo real;

Parâmetros Físicos - Dados-resultados da sonda CTD, responsável pela medição dos parâmetros físicos da água (condutividade, temperatura, turbidez e pressão)

Dados Sedimentológicos - informações sobre análise granulométrica das amostras de sedimentos coletadas na área em estudo;

Dados de Sensoriamento Remoto - dados de imagens de satélite e fotografias aéreas;

Mapas Temáticos - categoria que abrange os diversos tipos de mapas que podem ser construídos após a etapa de campo (Mapa de Uso do Solo, Mapa de Geologia, Mapa de Vegetação, Mapas Geofísicos (sísmica, side scan sonar, GPR), Mapa de Dinâmica Costeira, entre outros).

Numa primeira instância, seguindo a metodologia do GeoFrame, as categorias dos dados serão organizadas em forma de PACOTES do UML. Estes são grupos que contém CLASSES do banco de dados, além de outros pacotes, representados por uma ficha de separação com uma aba acima; onde dentro da ficha localizam-se todos os elementos dos pacotes (classes ou outros pacotes) e o nome do pacote é colocado na aba (Fig. 4). Assim, utilizando esse conceito de pacote, na primeira etapa delimita-se a região geográfica e os tipos de categorias de dados (Fig. 5).

SEGUNDA ETAPA DA MODELAGEM Após definidos os principais pacotes, é necessário detalhar cada pacote, identificando as classes que compõem cada um deles e as associações entre elas. Para não mostrar uma modelagem muito extensa, o pacote de Dados de Perfis de Praia foi escolhido para detalhamento nas eta-

\begin{tabular}{|c|}
\hline Nome do Pacote \\
\hline <elementos do pacote> \\
\hline
\end{tabular}

Figura 4 - Estrutura de um Pacote em UML (Unified Modeling Language) 


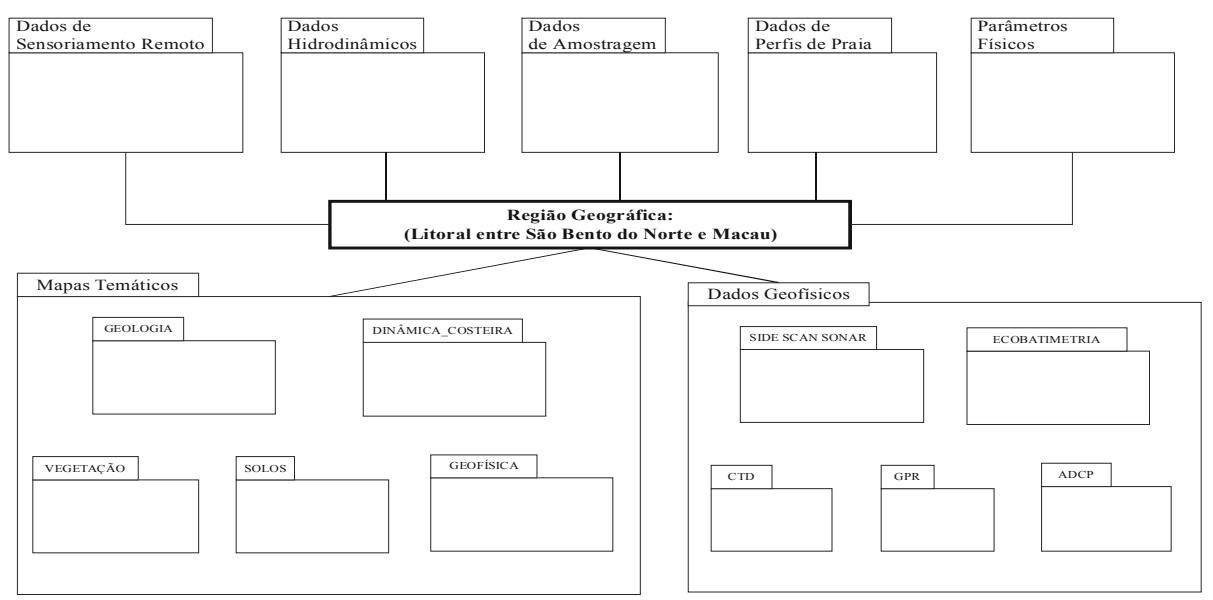

Figura 5 - Primeira Etapa da Modelagem Conceitual do GeoFrame (Filho 2000) aplicado ao Litoral Setentrional do Rio Grande do Norte, entre os municípios de São Bento do Norte e Macau.

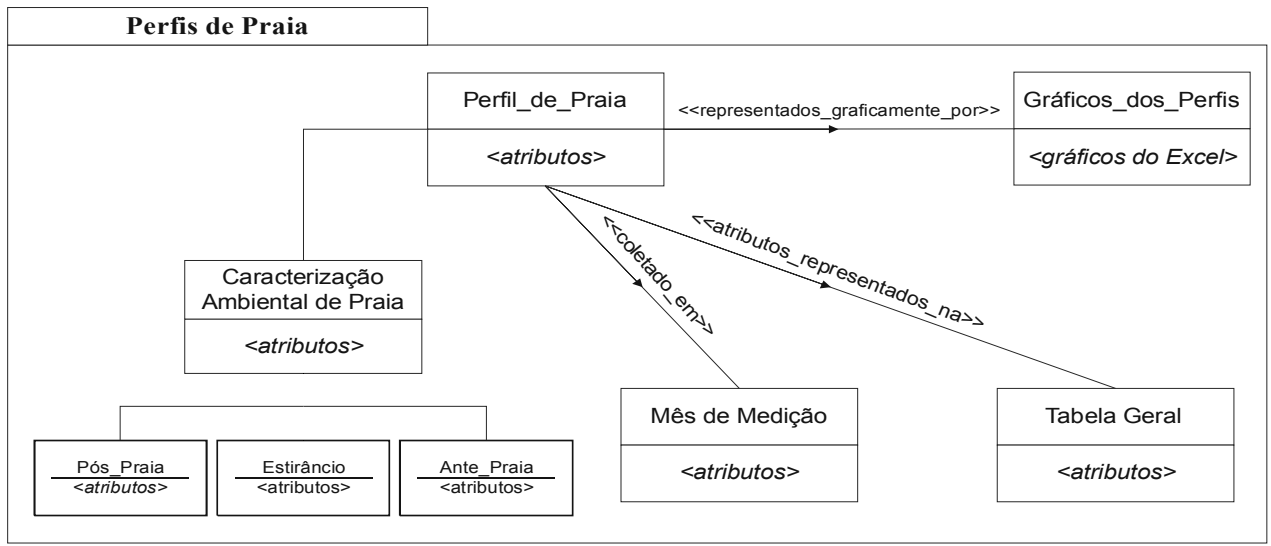

Figura 6 - Segunda Etapa da Modelagem Conceitual do GeoFrame com o detalhamento do pacote Perfis de Praia e as associações existentes entre as suas classes aplicadas a área de estudo.

pas seguintes (Fig. 6).

TERCEIRA ETAPA DA MODELAGEM Nessa última etapa define-se o que é Objeto Convencional ( ), Objeto Geográfico ( ) e de que tipo (ponto, linha, polígono ou objeto complexo), e o Campo Geográfico ( ) e de que tipo (imagem, TIN, ponto regular, polígonos adjacentes...).

Todos esses conceitos serão reconhecidos de acordo com seus respectivos estereótipos. Por fim, são descritos os atributos de cada classe do pacote de Perfis de Praia (Fig. 7).

Modelo lógico A partir do modelo conceitual é gerado o modelo lógico. Neste nível é definido como as entidades serão armazenadas na estrutura do BD (em forma de tabelas, mapas, gráficos etc). Assim, o modelo lógico depende do tipo de SGBD que será utilizado na implementação. Nesse nível, cada classe do modelo conceitual será detalhada no seu modo de armazenamento. Por exemplo, as classes do pacote Perfis de Praia seriam assim discriminadas:

Classe Perfil de Praia - Deve ser armazenada uma imagem de satélite georreferenciada da área de estudo com os perfis de praia plotados. Também devem ser armazenadas fotografias da área;

Classe Gráfico dos Perfis - Gráficos em geral no formato .XLS; Classes Caracterização Ambiental de Praia, Pós-Praia, Estirâncio, Ante-praia, Tabela Geral, Tabela de Dados e Mês de Medição - Tabelas com extensão .DBF, onde cada uma possui os atributos descritos no modelo conceitual.

Modelo físico Nessa etapa são definidos detalhes de implementação dos dados, com descrição da estrutura de armazenamento e os métodos utilizados para acessar os dados efetivamente. Estes fatores estão diretamente relacionados a um SGBD específico e permitem ao projetista planejar aspectos ligados à eficiência do sistema de banco de dados.

Uma das telas do banco de dados construído encontra-se exibida na Figura 8 abaixo, onde 6 perfis de praia estão representados em uma imagem de satélite georreferenciada e ao selecionar o Perfil 1, várias informações aparecem sobre ele (uma tabela de detalhes, um gráfico e uma foto da área). Os pontos em vermelhos são os pontos iniciais da medição de cada perfil. 
Desenvolvimento e aplicação de um banco de dados geográficos na elaboração de mapas da morfodinâmica costeira costeira e sensibilidade ambiental ao derramamento de óleo em áreas costeiras localizadas no estado do Rio Grande do Norte

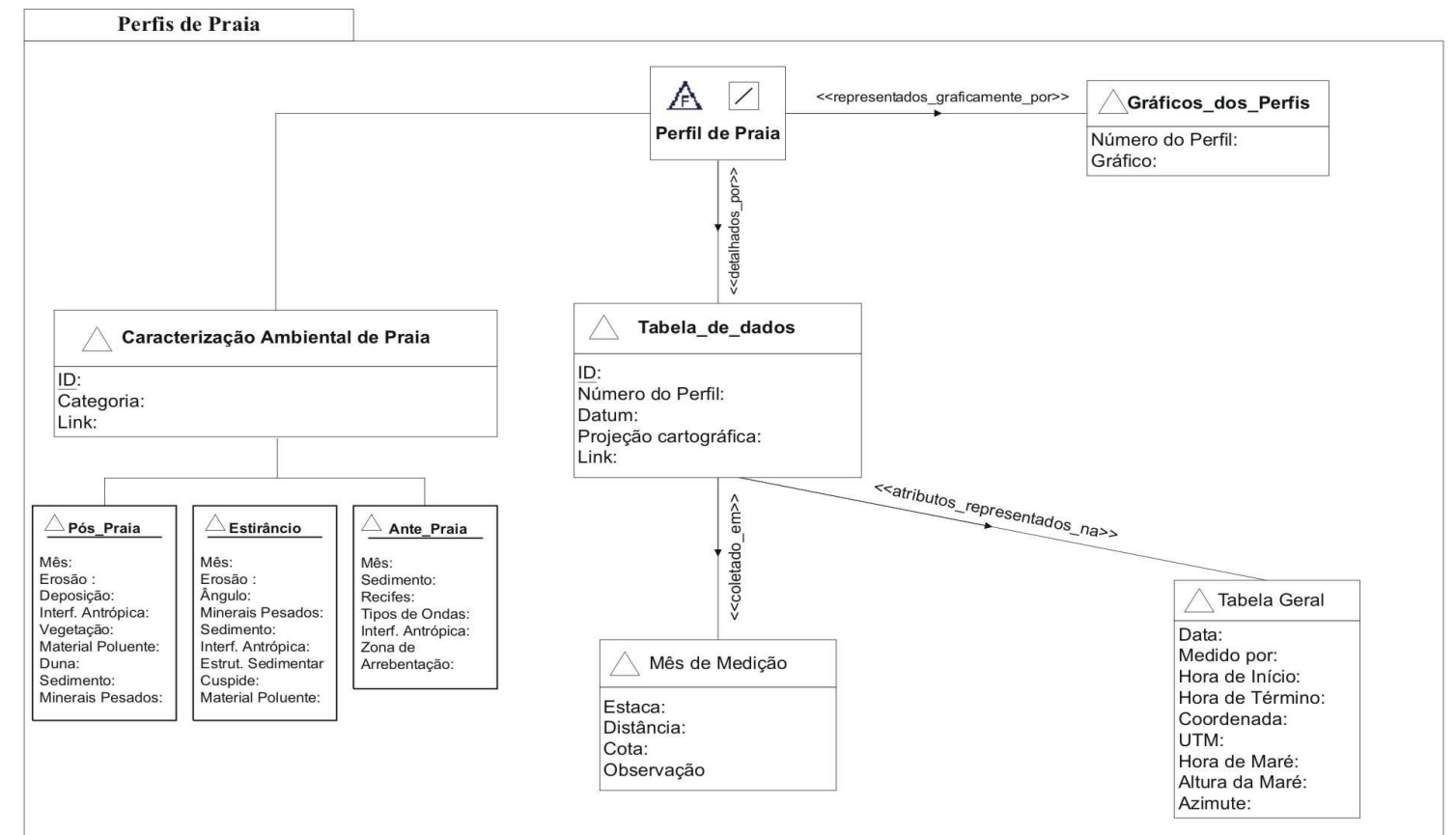

Figura 7 - Terceira Etapa da Modelagem Conceitual do Geoframe com o detalhamento dos atributos das classes do pacote Perfis de Praia e suas representações para a área de estudo.

Seguindo esse método, modelagem e desenvolvimento de banco de dados, foi possível desenvolver todo o banco de dados implementando todos os pacotes descritos na primeira etapa do Geoframe.

ACESSOAOSDADOS DO BDGPARADETERMINAÇÃODA VARIAÇÃODAMORFODINÂMICACOSTEIRAE DASENSIBILIDADEAMBIENTALAODERRAMAMENTODEÓLEODA ÁREA DE ESTUDO Concluído o desenvolvimento do banco de dados geográficos, algumas informações consideradas importantes foram extraídas para outros objetivos serem atingidos.

Extração de dados do BDG para elaboração de Mapas de Morfodinâmica Costeira da área $\mathrm{O}$ método aplicado na elaboração de mapas de morfodinâmica costeira em datas distintas baseou-se em dados digitais de sensoriamento remoto acessados do BDF. Esses dados são compostos por cartas topográficas da SUDENE (SB-24-X-D-II Macau e SB-24-X-D-III São Bento do Norte), ambas com escala de 1:100.000, e por imagens multiespectrais Landsat (duas Landsat 5-TM de datas 02/08/1989 e 13/06/2000, e um Landsat 7-ETM ${ }^{+}$datada 05/04/2001) com resolução espacial de $30 \mathrm{~m}$ e as tábuas de maré correspondentes a baixa-mar e preamar.

Dessa maneira, foram realizados cruzamentos dentro do SIG dos mapas de 1989, 2000 e 2001. A partir dos resultados obtidos foi possível avaliar as mudanças na linha de costa ao longo do tempo. Todos os dados digitais necessários foram resgatados do BDG e introduzidos no SIG para confecção da linha de costa para cada período das imagens. A elaboração da linha de costa foi obtida através da digitalização em tela ("heads up") para a imagem de cada período e a partir destas foram confeccionados polígonos correspondentes às áreas que sofreram erosão, acresção ou sem nenhuma modificação. As áreas $\left(\mathrm{m}^{2}\right)$ destes polígonos foram cal- culadas, sendo consideradas estimativas e não valores reais, devido aos erros inerentes às distorções neste trabalho (distorções das cartas topográficas e das imagens, resolução das imagens, tábua de maré e erro de digitalização dos vetores). No entanto, os valores obtidos servem para auxiliar outros trabalhos e/ou planejamentos, apontando áreas críticas, quanto às mudanças da morfologia da linha de costa.

Extração de dados do BDG para elaboração de Mapas de Sensibilidade Ambiental ao derramamento de óleo entre a área de Galinhos e São Bento do Norte As Cartas de Sensibilidade Ambiental para Derramamentos de Óleo (Cartas SAO) constituem um componente essencial e fonte de informação primária para o planejamento de contingência e avaliação de danos em casos de derramamento de óleo (qualquer forma de liberação de óleo para o ambiente, incluindo o despejo, escape, vazamento e transbordamento). Ademais, as cartas SAO representam uma ferramenta fundamental para o balizamento das ações de resposta a vazamentos de óleo, na medida em que, ao identificar aqueles ambientes com prioridade de preservação, permitem o direcionamento dos recursos disponíveis e a mobilização mais eficiente das equipes de proteção e limpeza. Essas cartas são desenvolvidas pelo Ministério do Meio Ambiente (MMA).

Os mapas de sensibilidade ambiental para derramamentos de óleo (MSAs) baseiam-se nas Cartas SAO e apresentam características semelhantes. O grande diferencial entre eles é que as Cartas SAO são documentos oficiais do Governo Federal, elaboradas pelo Ministério do Meio Ambiente; enquanto que, os MSAs são documentos locais elaborados para estudos específicos de áreas costeiras.

Os MSAs contêm informação básica de componentes costeiros, geomorfológicos, hidrodinâmicos e oceanográficos. Eles indicam áreas de conservação, recreação e assentamentos urbanos 


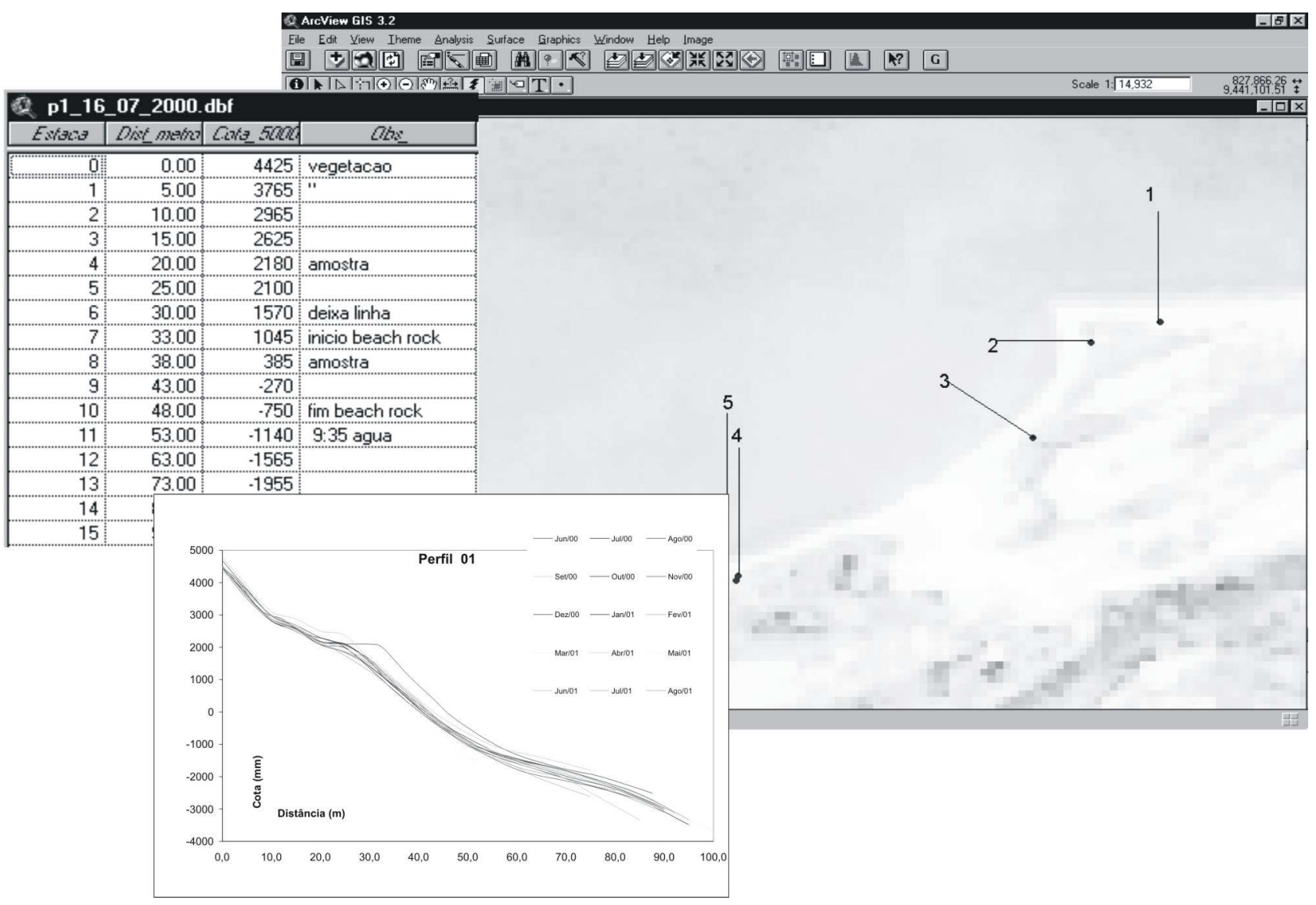

Figura 8 - Tela do SIG com perfis de praia plotados e as diversas formas de armazenamento (tabela, fotos e gráficos) ligadas ao perfil.

costeiros. A produção deles torna-se um elemento de grande importância no estudo ambiental, na análise de possíveis mudanças na área e nas prováveis conseqüências que essas mudanças podem acarretar. Trata-se de uma ferramenta poderosa, que pode orientar na tomada de decisões.

De acordo com MMA (2002), as cartas de sensibilidade incluem três tipos de informações principais: sensibilidade dos ecossistemas costeiros e marinhos; recursos biológicos; e usos humanos dos espaços e recursos (atividades socioeconômicas):

A) - Sensibilidade da Linha de Costa: Classifica as seções do litoral em hábitats, de acordo com suas características geomorfológicas, sensibilidade a derramamentos de óleo, persistência natural de óleo e condições de limpeza / remoção.

O sistema de classificação de sensibilidade é baseado no conhecimento das características geomorfológicas das áreas do litoral, considerando fatores como: grau de exposição à energia de ondas e marés; declividade do litoral e tipo do substrato, afetando sua permeabilidade e mobilidade. Para a classificação da sensibilidade da costa é fundamental o entendimento das interrelações entre os processos físicos, tipos de substrato e biota associada, que produzem ambientes geomorfológica e ecologicamente específicos, assim como padrões previsíveis de comportamento de óleo, padrões de transporte de sedimentos e impactos biológicos.

ISL (Índice de Sensibilidade do Litoral) é baseado nas caracte- rísticas geomorfológicas da costa, fundamentais para a determinação do grau de impacto e permanência do óleo derramado, assim como, em muitos casos, para os tipos de procedimento de limpeza passíveis de serem empregados. A geomorfologia é, também, determinante para o tipo e a densidade das comunidades biológicas presentes na área.

Cada ISL indica a sensibilidade de cada trecho da costa, que varia de 1 a 10, de acordo com as características físicas, ou seja, se é praia arenosa, costão rochoso, mangue, planície de maré entre outros. Os ISL aqui utilizados foram baseados nas Especificações e Normas Técnicas para Elaboração de Cartas de Sensibilidade Ambiental para Derrames de Óleo (Cartas SAO), em vias de elaboração pelo Ministério do Meio Ambiente em 2002, baseado na classificação de sensibilidade ambiental adotada pelo NOAA (National Oceanic and Atmospheric Administration), como mostra a Tabela 1.

Uma vez determinado o índice de sensibilidade do litoral, este é representado por uma cor aplicada à linha de costa representando o limite entre terra e água (Tabela 2).

B) Usos Humanos dos Recursos (atividades socio-econômicas) As atividades socioeconômicas que caracterizam a ocupação dos espaços e os usos dos recursos costeiros e marinhos, como o turismo, a pesca, a aqüicultura e o extrativismo costeiro, são sensíveis aos impactos por derramamentos de óleo. Assim, praias de 
alto uso recreacional, marinas, áreas de proteção ambiental, sítios de mineração, sítios arqueológicos, por exemplo, são representados no mapa de sensibilidade, sempre que localizados em áreas que possam ser afetadas por derramamento de óleo. Os recursos socio-econômicos são agrupados em: áreas de alto uso recreacional e locais de acesso à linha de costa; áreas sob gerenciamento especial; locais de extração de recursos naturais; e localização de sítios arqueológicos, culturais e históricos. Os recursos de uso humano são indicados por ícones em preto e branco. Devem ser identificadas nos mapas as estradas secundárias, importantes para as operações de resposta, assim como locais de atracação, rampas para barcos, aeroportos, heliportos, depósitos e locais de concentração de equipamentos de contenção, limpeza e transporte.

Logo, para se obter os mapas de sensibilidade da área entre Galinhos e São Bento do Norte, foi necessário acessar o Banco de Dados Geográficos previamente desenvolvido, a fim de se extrair os dados importantes para a obtenção desses tipos de mapas.

Dessa forma, foram extraídos do BDG: o mapa de geomorfologia da área entre Galinhos e São Bento; dados hidrodinâmicos, especificamente energia das ondas e direção de correntes; dado de perfil de praia, como inclinação (ou declividade) do estirâncio e características do substrato, tais como granulometria e permeabilidade.

O grau de exposição à energia de ondas e marés e direção da corrente é importante pois o tempo de permanência do óleo em ambientes de alta energia de ondas e marés tende a ser menor do que em ambientes abrigados. Portanto, quanto maior a exposição à energia de ondas e marés, mais rápida será a limpeza natural da praia e menor será a sensibilidade ao óleo. A declividade da praia pode ser favorável ou não ao óleo. Litorais muito inclinados caracterizam-se pelo tempo mínimo de permanência do óleo. Quanto mais inclinado, melhor. $\mathrm{O}$ tipo de substrato determina ou afeta alguns parâmetros, como permeabilidade, mobilidade do sedimento e permanência do óleo, além da trafegabilidade de veículos.

Diante disso, foram escolhidos dois meses distintos (Junho/ 2000 e Dezembro/2000) e foram acessados do BDG os dados temporais relativos. Esses dados foram colocados em uma tabela (Tabela 3) a fim de se determinar o ISL da área, baseando-se nos parâmetros e ISLs definidos pelo MMA, anteriormente exibidos nas Tabelas 1 e 2 (Castro 2002).

RESULTADOS OBTIDOS Morfodinâmica Costeira Foram obtidos mapas da morfodinâmica costeira (Fig. 9) a partir do cruzamento das linhas de costa de três datas distintas em dois intervalos de tempo (1989-2000 e 2000-2001), apresentando áreas com intensa erosão e deposição (ou acresção) relacionados com os processos costeiros na área de estudo.

Sensibilidade Ambiental ao Derramamento de Óleo Após determinado os ISL da região, estes estão aptos a serem visualizados nos mapas temáticos (por exemplo o mapa de geomorfologia) ou mesmo sobre uma imagem de satélite com o auxílio do SIG utilizado. As Figuras 10a e 10b mostram os mapas de sensibilidade ambiental ao derramamento de óleo da área de estudo nos meses de junho/2000 e dezembro/2000, respectivamente.

Observando-se os índices de sensibilidade dos meses de junho e dezembro, percebeu-se um aumento destes no verão (dezembro) e esta diferença pode ser explicada por alguns parâmetros:

Caso 1: Aumento do ISL 2 para ISL 3: A presença de beachrocks como barreira ao óleo continua válida no mês de dezembro, mas a altura de ondas diminuiu de $43,7 \mathrm{~cm}$ para $17,2 \mathrm{~cm}$, fazendo com que o grau de exposição à energia de ondas diminua;

Caso 2: ISL 2 em junho e em dezembro esse ISL aumentou para 4: A altura de ondas diminuiu de $45,2 \mathrm{~cm}$ para $10,7 \mathrm{~cm}$, diminuindo o grau de exposição à energia de ondas, sendo propício ao óleo permanecer mais tempo na área; notou-se uma diminuição na declividade do estirâncio $\left(\right.$ de $16^{\circ}$ para $\left.9^{\circ}\right)$.

Caso 3: Aumento do ISL 3 para ISL 4: A altura de ondas diminuiu de $40,1 \mathrm{~cm}$ para $14 \mathrm{~cm}$, diminuindo o grau de exposição à energia de ondas; a direção da corrente no mês de dezembro $\left(275^{\circ}\right)$, deixa o óleo muito mais próximo à costa do que o mês de junho $\left(290^{\circ}\right)$, que leva o óleo para a área offshore; quanto mais veloz a corrente, mais rápido o fluxo do óleo.

Caso 4: ISL 10 na área de mangue. A área de mangue apresenta o maior índice de sensibilidade devido aos seus próprios fatores naturais: vegetação associada com alta diversidade biológica; tipo de substrato propício à fixação do óleo; não ocorre limpeza natural, é necessária limpeza manual.

CONCLUSÕES Algumas conclusões importantes foram verificadas nesse trabalho:

Sistemas de Informações Geográficas e Banco de Dados Geográficos A utilização de SIG em estudos ambientais costeiros mostrou-se satisfatória, pois foi possível visualizar os dados armazenados nas mais diversas formas: tabelas, gráficos, imagens, mapas, fotografias dentre outros.

Banco de Dados Geográficos (BDG), componente do SIG que armazena e recupera dados, é de fundamental importância quando se pretende trabalhar com dados espaciais e temporais, pois ele é capaz de armazenar informações geográficas que variam ao longo do tempo, permitindo a análise temporal dos dados armazenados;

A modelagem conceitual de um banco de dados geográficos é de extrema importância, visto que é nessa fase que são definidos todos os dados a serem inseridos no BDG, bem como todos os relacionamentos existentes entre eles;

modelo conceitual utilizado, o Geoframe, atendeu às necessidades para se chegar ao objetivo do trabalho. Como se tratavam de vários tipos de dados, foi possível organizá-los em categorias e classes, de acordo com parâmetros específicos Geoframe;

A modelagem conceitual foi útil no desenvolvimento do BDG, pois facilitou a organização dos multidados e auxiliou na sua futura inserção no banco de dados;

Mapas de Morfodinâmica Costeira Ficou constatado, conforme os mapas morfodinâmicos para os anos de 1989, 2000 e 2001, a contínua progradação da barra arenosa da ilha barreira da Ponta do Tubarão para W-SW e do esporão arenoso da Barra do Fernandez para $\mathrm{W}$.

No entanto, na comparação entre as datas de 1989-2000 houve uma quebra da barra arenosa da Ponta do Tubarão devido a retirada do pier que ligava a Ponta do Tubarão ao continente em 1997, o que fez com que ocorressem várias mudanças da morfologia costeira durante este período.

Ocorreu também, neste mesmo período, a migração da outra barra arenosa da Ponta do Tubarão para W. No período de 20002001, o efeito erosivo na região continua intenso, principalmente nas áreas da ilha barreira, no esporão arenoso, no Campo Macau, área de exploração da indústria petrolífera;

Mapas de Sensibilidade Ambiental ao Derramamento de Óleo Os mapas de sensibilidade ambiental ao derramamento de óleo 
Tabela 1 - indice de sensibilidade ambiental ("Environmental Sensitivity Index - ESI”) ao petróleo e seus derivados e características do litoral-NOAA. Fonte: MMA (2002).

\begin{tabular}{|c|c|c|c|c|c|c|c|c|c|}
\hline \multirow{2}{*}{$\begin{array}{l}\text { DICE DE } \\
\text { IBILIDADE } \\
\text { BIENTAL } \\
\text { (ESI) } \\
\end{array}$} & \multirow{2}{*}{$\begin{array}{l}\text { GRAU DE } \\
\text { EXPOSIÇÃOO } \\
\text { A ONDAS }\end{array}$} & \multicolumn{2}{|c|}{ FAIXA INTERMARÉS } & \multicolumn{4}{|c|}{$\begin{array}{l}\text { SUBSTRATO } \\
\end{array}$} & \multirow[t]{2}{*}{ BIOTA } & \multirow[t]{2}{*}{ TIPO DE LITORAL } \\
\hline & & Inclinação & Largura & Tipo & Mobilidade & $\begin{array}{c}\text { Penetração } \\
\text { do óleo }\end{array}$ & Trafegabilidade & & \\
\hline 1 & Alto & $>30^{\circ}$ & Estreita & $\begin{array}{l}\text { Costão } \\
\text { rochoso }\end{array}$ & Fixo & Impermeável & Não & $\begin{array}{c}\text { Aclimatada a } \\
\text { altos impactos } \\
\text { hidráulicos e } \\
\text { pressão }\end{array}$ & $\begin{array}{c}\text { Costões rochosos } \\
\text { expostos, estruturas } \\
\text { artificiais impermeáveis }\end{array}$ \\
\hline 2 & Alto & $<30^{\circ}$ & Larga & $\begin{array}{l}\text { Leito } \\
\text { rochoso }\end{array}$ & Fixo & Impermeável & Não & $\begin{array}{l}\text { Aclimatada a } \\
\text { altos impactos } \\
\text { hidráulicos } \\
\text { e pressão }\end{array}$ & $\begin{array}{l}\text { Plataformas erodidas } \\
\text { pela ação das ondas }\end{array}$ \\
\hline 3 & - & $<5^{\circ}$ & Larga & $\begin{array}{c}\text { Areia fina a } \\
\text { média } \\
(0,06 \text { a } 1 \mathrm{~mm})\end{array}$ & Baixa & $\begin{array}{l}\text { Semipermeável } \\
(<10 \mathrm{~cm})\end{array}$ & $\begin{array}{c}\text { Permite } \\
\text { tráfego de } \\
\text { veículos }\end{array}$ & Baixa densidade & $\begin{array}{l}\text { Praias de areia fina } \\
\text { ou média }\end{array}$ \\
\hline 4 & - & $5-15^{\circ}$ & Larga & $\begin{array}{l}\text { Areia grossa/ } \\
\text { grânulo } \\
(2-4 \mathrm{~mm})\end{array}$ & Alta & $\begin{array}{l}\text { Permeável } \\
(\leq 25 \mathrm{~cm})\end{array}$ & $\begin{array}{c}\text { Baixa } \\
\text { trafegabilidade } \\
\text { de veículos }\end{array}$ & Baixa densidade & $\begin{array}{l}\text { Praias de areia e } \\
\text { cascalho }\end{array}$ \\
\hline 5 & - & $8-15^{\circ}$ & - & $\begin{array}{l}\text { Areia e } \\
\text { cascalho }\end{array}$ & $\begin{array}{l}\text { Muito alta } \\
\text { durante } \\
\text { tempestades }\end{array}$ & $\leq 50 \mathrm{~cm}$ & $\begin{array}{c}\text { Baixa } \\
\text { trafegabilidade } \\
\text { de veículos }\end{array}$ & Muito baixa & $\begin{array}{l}\text { Praias de areia e } \\
\text { cascalho }\end{array}$ \\
\hline 6 & - & $10-20^{\circ}$ & - & Cascalho & Baixa & $\begin{array}{l}\text { Altamente } \\
\text { permeável } \\
(\leq 100 \mathrm{~cm})\end{array}$ & $\begin{array}{l}\text { Muito baixa } \\
\text { trafegabilidade }\end{array}$ & $\begin{array}{c}\text { Infauna e } \\
\text { epifauna } \\
\text { muito baixas }\end{array}$ & $\begin{array}{c}\text { Praias de } \\
\text { cascalho e } \\
\text { enrocamentos }\end{array}$ \\
\hline 7 & $\begin{array}{c}\text { Variável de } \\
\text { alto a médio }\end{array}$ & $<3^{\circ}$ & $\begin{array}{c}\text { Estreita a } \\
\text { muito larga }\end{array}$ & Areia & - & $\begin{array}{c}\text { Penetração } \\
\text { limitada }\end{array}$ & Baixa & Muito baixa & $\begin{array}{l}\text { Áreas intermarés } \\
\text { planas expostas }\end{array}$ \\
\hline 8 & Baixo & $>15^{\circ}$ & Estreita & $\begin{array}{c}\text { Leito rochoso } \\
\text { (algum sedimento) }\end{array}$ & - & - & Baixa & $\begin{array}{c}\text { Coberto de algas } \\
\text { e outros } \\
\text { organismos }\end{array}$ & $\begin{array}{l}\text { Costões rochosos } \\
\text { abrigados }\end{array}$ \\
\hline 9 & Baixo & $<3^{\circ}$ & $\begin{array}{c}\text { Estreita a } \\
\text { muito larga }\end{array}$ & Lamoso & - & $\begin{array}{c}\text { Baixa } \\
\text { permeabilidade }\end{array}$ & Muito baixa & $\begin{array}{c}\text { Alta densidade } \\
\text { de infauna }\end{array}$ & $\begin{array}{l}\text { Áreas intermarés } \\
\text { planas abrigadas }\end{array}$ \\
\hline 10 & Médio a baixo & $<10^{\circ}$ & Variável & Areia lamosa & Baixa & $\begin{array}{c}\text { Baixa } \\
\text { permeabilidade }\end{array}$ & Muito baixa & $\begin{array}{c}\text { Vegetação } \\
\text { associada com } \\
\text { alta diversidade }\end{array}$ & $\begin{array}{l}\text { Marismas, } \\
\text { manguezais }\end{array}$ \\
\hline
\end{tabular}

Tabela 2 - Esquema de cores para classificação do Indice de Sensibilidade do Litoral (ISL). Fonte: MMA (2002).

\begin{tabular}{|c|c|c|}
\hline ÍNDICE & COR & TIPOS DE COSTA \\
\hline ISL 1 & & $\begin{array}{ll}\text { - } & \text { Costões rochosos lisos } \\
\text { - } & \text { Falésias em rochas sedimentares } \\
& \text { Estruturas artificiais lisas }\end{array}$ \\
\hline ISL 2 & & $\begin{array}{l}\text { Terraço, plataforma de abrasão ou terraço arenítico exumado, de } \\
\text { declividade média, exposto. }\end{array}$ \\
\hline ISL 3 & & $\begin{array}{l}\text { - } \quad \text { Praias dissipativas, de areia fina a média, expostas. } \\
\text { - } \quad \text { Praias de areia fina a média, abrigadas. } \\
\text { - Restingas - faixa contígua à praia, ainda sujeita à ação de ressacas }\end{array}$ \\
\hline ISL 4 & & $\begin{array}{l}\text { - Praias de areia grossa } \\
\text { - Praias intermediárias, de areia média a fina, expostas. }\end{array}$ \\
\hline ISL 5 & & $\begin{array}{l}\text { - Praias mistas de cascalho e areia, areia e conchas, ou areia e corais } \\
\text { - Terraço ou plataforma de abrasão de superfície irregular ou coberto de } \\
\text { vegetação. }\end{array}$ \\
\hline ISL 6 & & $\begin{array}{l}\text { - } \quad \text { Praias de cascalho (seixos e calhaus) } \\
\text { - } \quad \begin{array}{l}\text { Enrocamento de tálus ("rip-rap", quebra-mar) expostos } \\
\text { Plataforma ou terraço recoberto por concreções lateríticas ou } \\
\text { bioconstrucionais }\end{array} \\
\end{array}$ \\
\hline ISL 7 & & $\begin{array}{l}\text { - Planície de maré arenosa exposta } \\
\text { - Terraço de baixa-mar }\end{array}$ \\
\hline ISL 8 & & $\begin{array}{l}\text { Escarpa / encosta de rocha lisa abrigada } \\
\text { - } \quad \text { Escarpa / encosta de rocha não-lisa abrigada } \\
\text { Enrocamentos abrigados }\end{array}$ \\
\hline ISL 9 & & $\begin{array}{l}\text { - Planícies de maré arenosa / lamosa abrigada } \\
\text { - Terraço de baixa-mar lamoso abrigado / recifes }\end{array}$ \\
\hline ISL 10 & & $\begin{array}{l}\text { - Terrenos alagadiços, banhados, brejos, margens de rios e lagoas. } \\
\text { - Marismas } \\
\text { Mangues e pântanos costeiros }\end{array}$ \\
\hline
\end{tabular}

(MSAs) são ferramentas importantes para a identificação da sensibilidade da linha de costa diante da presença do óleo, bem como as atividades sócio-econômicas existentes e as medidas de proteção possíveis;

Utilizando-se os dados espaciais armazenados e as vantagens que o SIG apresenta, foi possível gerar dois mapas de sensibilidade ambiental das áreas situadas entre Galinhos e São Bento do Norte, a fim de verificar se haveria alguma mudança no ISL em épocas diferentes (Junho/2000 e Dezembro/2000).

Alguns dados foram primordiais na elaboração dos MSAs, tais como litologia da área, grau de exposição à energia de ondas, direção de correntes, declividade do litoral, com destaque à inclinação do estirâncio e ao tipo do substrato do local.

Em junho / 2000 a sensibilidade variou de 2 a 3, tendo como valor máximo o índice $10 \mathrm{em}$ zonas de manguezais e planícies estuarinas e em dezembro / 2000 o índice de sensibilidade foi 4, também tendo como valor 10 as áreas de mangues e planícies estuarinas.

Em linhas gerais, a linha de costa entre Galinhos e São Bento do Norte mostrou-se bem mais sensível durante o mês de dezembro 
Desenvolvimento e aplicação de um banco de dados geográficos na elaboração de mapas da morfodinâmica costeira costeira e sensibilidade ambiental ao derramamento de óleo em áreas costeiras localizadas no estado do Rio Grande do Norte

Tabela 3 - Determinação dos Índices de Sensibilidade do Litoral (ISL) das áreas entre Galinhos e São Bento do Norte / RN nos meses de Junho/2000 e Dezembro/2000 (Fonte: Castro 2002).

\begin{tabular}{|c|c|c|c|c|c|}
\hline \multicolumn{6}{|c|}{ JUNHO / 2000} \\
\hline Litologia & $\begin{array}{c}\text { Altura } \\
\text { das ondas } \\
\text { (cm) }\end{array}$ & $\begin{array}{l}\text { Direção das } \\
\text { correntes } \\
(A z)\end{array}$ & $\begin{array}{c}\text { Inclinação } \\
\text { do } \\
\text { estirâncio }\end{array}$ & $\begin{array}{c}\text { Tipo } \\
\text { de } \\
\text { substrato }\end{array}$ & $I S L$ \\
\hline Presença de beachrocks & 45,2 & $300^{\circ}$ & $16^{\circ}$ & Areia Média & 2 \\
\hline Praia de areia fina & 40,1 & $290^{\circ}$ & $0^{\circ}$ & Areia Fina & 3 \\
\hline Beachrocks & 43,7 & $288^{\circ}$ & $15^{\circ}$ & Areia Média & 2 \\
\hline Manguezal & & & & & 10 \\
\hline \multicolumn{6}{|c|}{ DEZEMBRO / 2000} \\
\hline Presença de beachrocks & 10,7 & $270^{\circ}$ & $9^{\circ}$ & Areia Média & 4 \\
\hline Praia de areia fina & 14 & $275^{\circ}$ & $12^{\circ}$ & Areia Média & 4 \\
\hline Beachrocks & 17,2 & $270^{\circ}$ & $5^{\circ}$ & $\begin{array}{l}\text { Areia fina } \\
\text { a média }\end{array}$ & 3 \\
\hline Manguezal & & & & & 10 \\
\hline
\end{tabular}

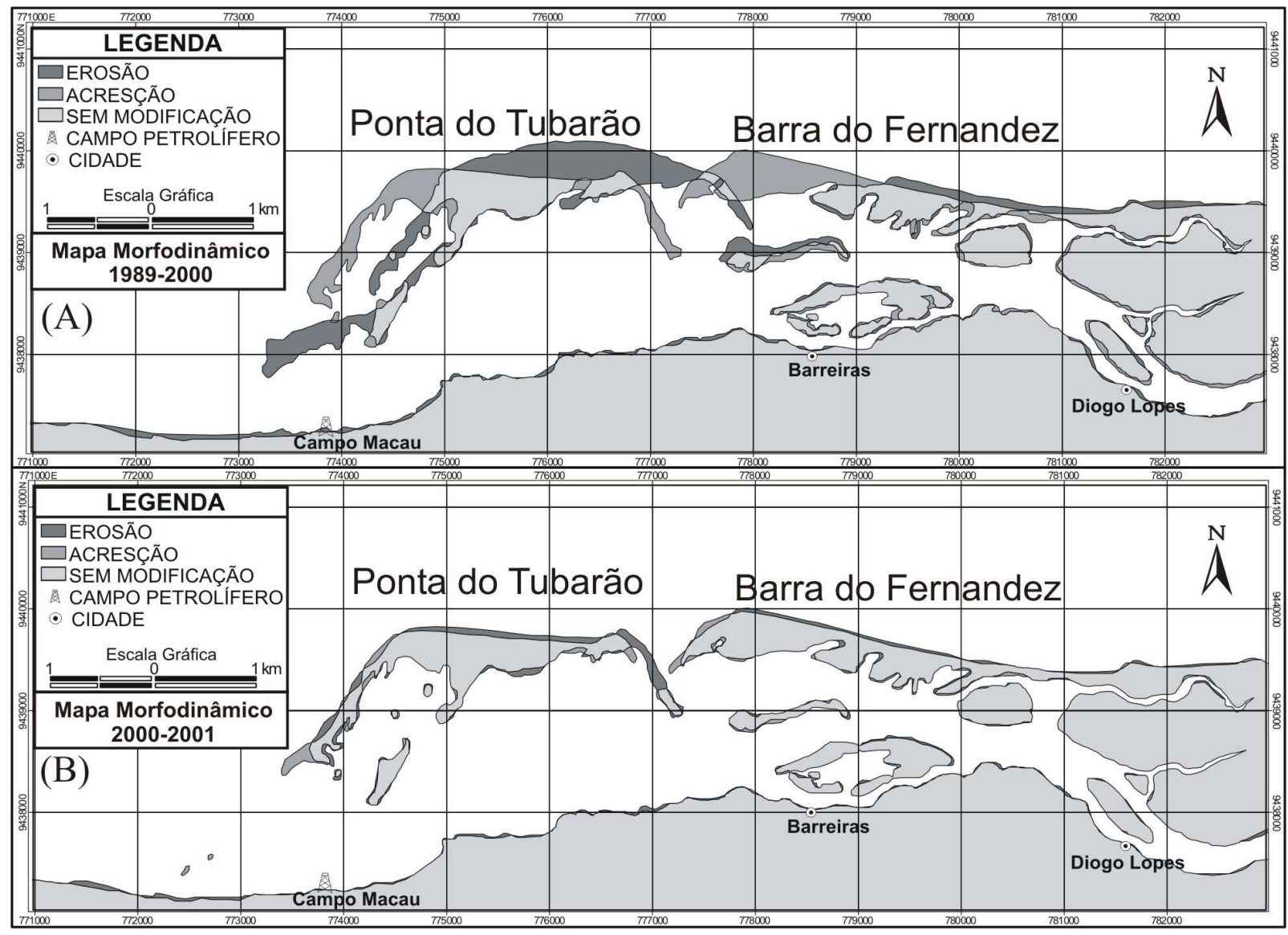

Figura 9 - Mapas Morfodinâmicos para as áreas da Barra do Fernandez e Ponta do Tubarão, Litoral Setentrional do Rio Grande do Norte: (A) Variações entre os anos de 1989 e 2000; (B) Variações entre os anos de 2000 e 2001. Áreas quantificadas quanto acresção, erosão e sem modificação, com indicação do CampoPetrolifero Macau (PETROBRÁS).

do que durante o mês de junho. Isso pode ser explicado porque em junho os dados hidrodinâmicos (altura de ondas e direção de correntes), apresentaram-se mais propícios para uma limpeza natural e afastamento do óleo da costa.
Agradecimentos A Agencia Nacional do Petróleo (ANP) pela concessão de bolsa à primeira autora durante a execução deste trabalho, por meio do PRH22-ANP; aos Projetos MAMBMARE (FINEP/PETROBRAS/CTPETRO), PETRORISCO(FINEP/CNPq/ 

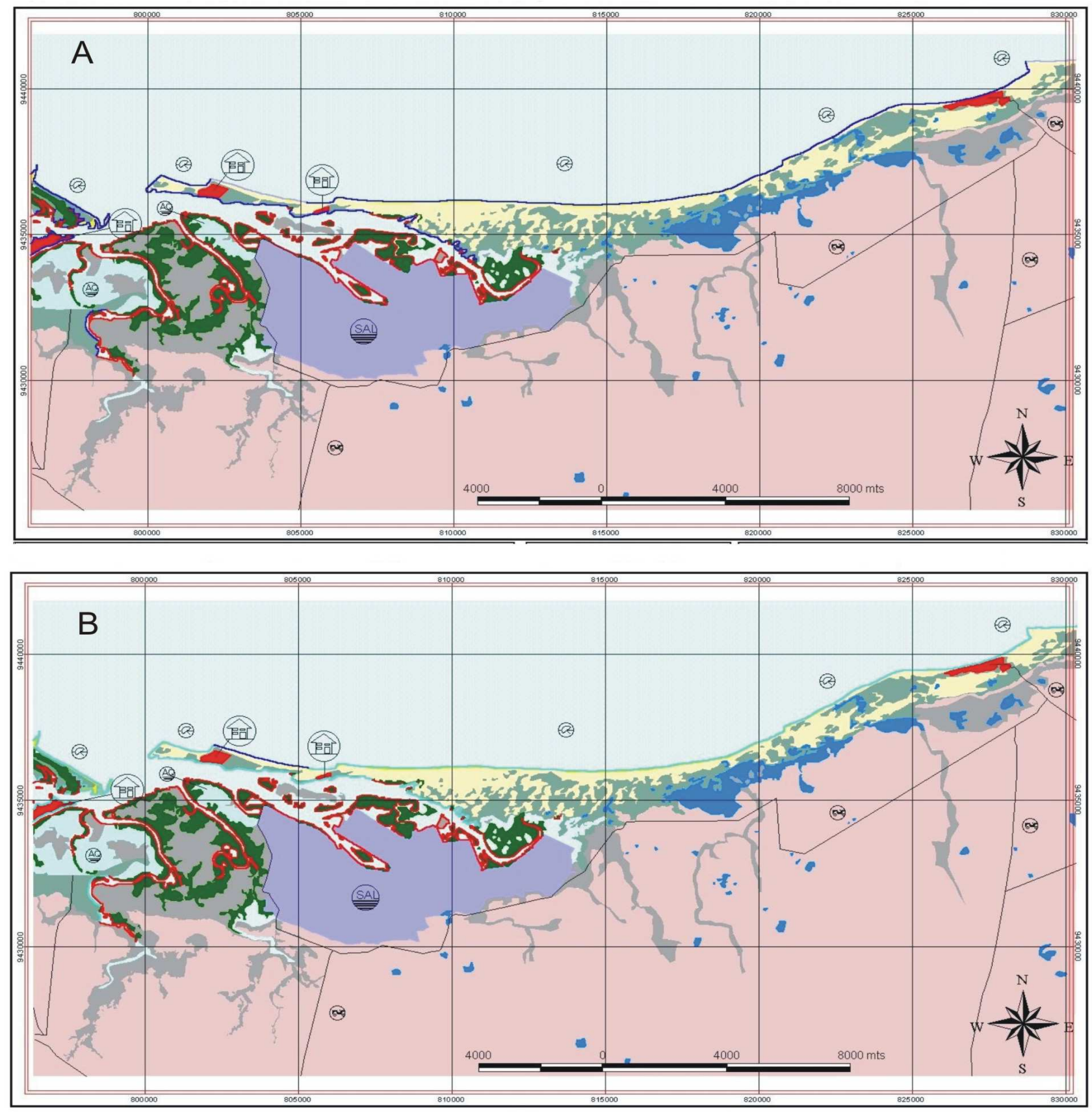

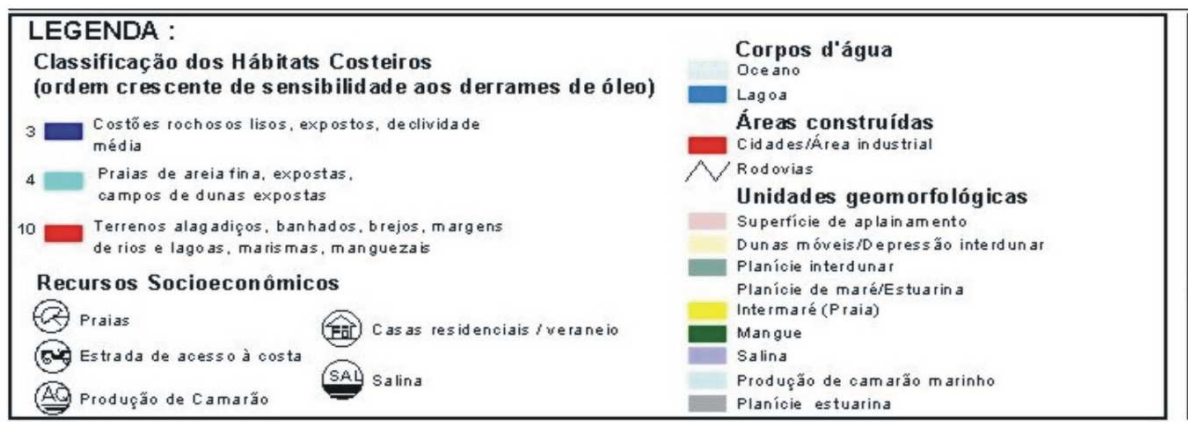

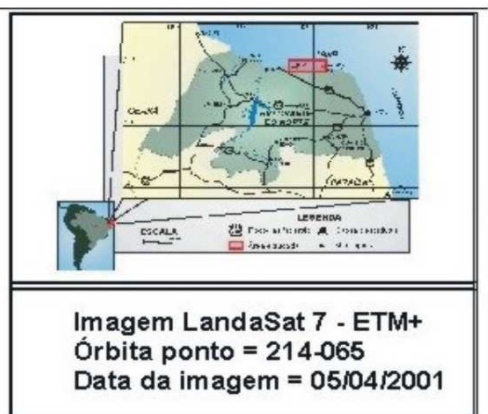

Figura 10 - Mapas de sensibilidade ambiental ao derramamento de óleo da área de estudo: (A) - em Junho de 2000 e (B) em Dezembro de 2000. 
Desenvolvimento e aplicação de um banco de dados geográficos na elaboração de mapas da morfodinâmica costeira costeira e sensibilidade ambiental ao derramamento de óleo em áreas costeiras localizadas no estado do Rio Grande do Norte

CTPETRO) e PROBRAL 150-02 (CAPES/DAAD) pelo suporte financeiro. Ao Programa de Pós-Graduação em Geodinâmica e
Geofísica e Departamento de Geologia da UFRN pela infraestrutura necessária. Aos revisores da RBG pelas sugestões ao manuscrito.

\section{Referências}

Bahr H.P., Karlsruhe. 1999. GIS Introduction. In: Bahr H.P. e Vogtle T. (eds.) GIS for Environmental Monitoring. Alemanha, 1-9.

Caldas L.H. de O. 1996. Geologia Costeira da Região de São Bento do Norte e Caiçara, Litoral Potiguar. Departamento de Geologia, Universidade Federal do Rio Grande do Norte, Natal, Relatório de Graduação, 83 p.

Caldas L.H. de O. 1998. Estudo Geológico e Geofisico da Falha de Carnaubais, Bacia Potiguar-RNe Implicações Neotectônicas. PósGraduação em Geodinâmica e Geofísica, Universidade Federal do Rio Grande do Norte, Natal, Dissertação de Mestrado, 89 p.

Castro A.F. 2002. Modelagem e desenvolvimento de um banco de dados geográficos: Aplicação à elaboração de mapas de sensibilidade ambiental ao derramamento de óleo na área costeira entre Galinhos e São Bento do Norte - RN. Dissertação de Mestrado, Universidade Federal do Rio Grande do Norte, 87 p.

Dantas E.P. 1998. Gravimetria e Sensoriamento Remoto: Uma Aplicação ao Estudo da Tectônica Recente entre Macau e São Bento do Norte $(R N)$. Dissertação de Mestrado, Universidade Federal do Rio Grande do Norte, $97 \mathrm{p}$

Filho J.L. 1997. Modelos Conceituais de Dados para Sistemas de Informações Geográficas. Exame de qualificação, Instituto de Informática, Universidade Federal do Rio Grande do Sul, 121 p.

Filho J.L, Iochpe C., Hasenack H., Weber E. J. 1999. Modelagem Conceitual de Banco de Dados Geográficos: o estudo de caso do Projeto PADCT / CIAMB. In: Banco de Artigos, Centro de Recursos Idrisi, Instituto de Biociências, Universidade Federal do Rio Grande do Sul, Porto Alegre. Disponível em: http://www.ecologia.ufrgs.br/ idrisi/artigos/>. Acesso em: 24 set. 2001.

Filho J.L. 2000. Projeto Conceitual de Banco de Dados Geográficos através da reutilização de Esquemas, utilizando Padrões de Análises e um Framework Conceitual. Tese de Doutorado, Instituto de Informática, Universidade Federal do Rio Grande do Sul, 212 p.

Gomes M.K.N.F. 1997. Sistemas de Informações Geográficas como Base da Interface do Sistema SAGRI - Sistema Inteligente de Apoio à Atividade Agrícola. RElatório de Graduação, Departamento de Informática e Matemática Aplicada, Universidade Federal do Rio Grande do Norte, $52 \mathrm{p}$.

Heuser C.A. 2001. Projeto de Banco de Dados. 4 ed. Porto Alegre, Editora Sagra Luzzato, $204 \mathrm{p}$

Hustedt S. 2000. Aeolian morphodynamics in the region of São Bento do Norte on the NE-coast of Brazil. M.Sc. Thesis, Institute of Geo- sciences, Christian Albrechts University, Kiel, Germany, 69 p.

Larman C. 2000. Utilizando UML e Padrões - Uma introdução à análise e ao projeto orientados a objetos. Trad.Luiz A. Meirelles Salgado. 1 ed. Porto Alegre, Bookman, 491p.

Lima Z.M.C. 1993. Estudo Comparativo e Caracterização Ambiental da Península de Galinhos - RN. Monografia de Graduação, Departamento de Geografia, Universidade Federal do Rio Grande do Norte, $91 \mathrm{p}$.

Lima Z.M.C., Amaro V.E., Vital H. 2000. Dinâmica Ambiental da Península de Galinhos - RN (NE Brasil). In: Simp. Bras. Praias Arenosas: morfodinâmica, ecologia, usos, riscos e gestão. Itajaí, Anais..., 1:137138.

Lima Z.M.C., Amaro V.E., Vital H. 2001. Monitoramento da Variação da linha de costa de Galinhos / RN utilizando fotografias aéreas e imagens Landsat5 TM e Landsat 7 ETM +. In: Congr. Abequa, 8, Imbé, RS, Resumos, v. 1, p. 551-552.

MMA - Ministério do Meio Ambiente. 2002. Especificações e Normas Técnicas para Elaboração de Cartas de Sensibilidade Ambiental para Derramamentos de Óleo. Ministério do Meio Ambiente, Secretaria de Qualidade Ambiental nos Assentamentos Humanos, Programa de Proteção e Melhoria da Qualidade Ambiental, Projeto de Gestão Integrada dos Ambientes Costeiro e Marinho.

Secretaria de Recursos Hídricos. 2001. Bacias Hidrográficas do Rio Grande do Norte. Disponível em: http://www.serhid.rn.gov.br/ detalhe.asp? IdPublicacao =151. Acesso em: 07 nov. 2001 .

Silveira I.M., Vital H., Amaro V.E. 2001. Vulnerabilidade e Sensibilidade da Região Costeira de Guamaré-RN. In: SBG, Simp. Geol. Nordeste 17, Natal/, Atas, p. 41

Silveira I.M. 2002. Estudo Evolutivo das Condições Ambientais da Região Costeira do Município de Guamaré - RN. Dissertação de Mestrado, Universidade Federal do Rio Grande do Norte, 172 p.

Tabosa W.F. 2001. Monitoramento Costeiro das Praias de São Bento do Norte e Caiçara do Norte, $R N$. Exame de qualificação, Pós-Graduação em Geodinâmica e Geofísica, Universidade Federal do Rio Grande do Norte, $13 \mathrm{p}$.
Manuscrito SR-07

Recebido em 17 de novembro de 2002

Revisão dos autores em 10 de marco de 2003 Revisão aceita em 03 de abril de 2003 